\title{
Recombinant Spider Silk Protein and Delignified Wood Form a Strong Adhesive System
}

\section{University, Aalto}

2021-12-22

University , A , Tersteegen , J , Sammaljarvi , J , Aranko , A S \& Linder , M B 2021 , '

Recombinant Spider Silk Protein and Delignified Wood Form a Strong Adhesive System ' ,

pÿACS Sustainable Chemistry \& Engineering , vol. 10 , no. 1 , pp. 552561 . https://doi.org/10.1021/acssuschemeng

http://hdl.handle.net/10138/340582

https://doi.org/10.1021/acssuschemeng.1c07043

cc_by

publishedVersion

Downloaded from Helda, University of Helsinki institutional repository.

This is an electronic reprint of the original article.

This reprint may differ from the original in pagination and typographic detail.

Please cite the original version. 


\section{Recombinant Spider Silk Protein and Delignified Wood Form a Strong Adhesive System}

Laura Lemetti, Jennifer Tersteegen, Juuso Sammaljärvi, A. Sesilja Aranko, and Markus B. Linder*

Cite This: ACS Sustainable Chem. Eng. 2022, 10, 552-561

Read Online

ABSTRACT: For developing novel fully biological materials, a central question is how we can utilize natural components in combination with biomimetic strategies in ways that both allow feasible processing and high performance. Within this development, adhesives play a central role. Here, we have combined two of nature's excellent materials, silk and cellulose, to function as an adhesive system. As an initial step in processing, wood was delignified. Without lignin, the essential microstructure and alignment of the wood remain, giving a strong scaffold that is versatile to process further. A recombinant spider silk protein was used as a fully biological and water-based adhesive. The adhesive strength was excellent with an average value of $6.7 \mathrm{MPa}$, with a maximum value of up to $10 \mathrm{MPa}$. Samples of different strengths showed characteristic

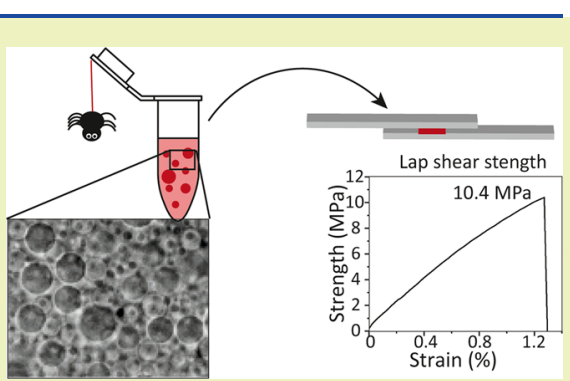
features, with high tear-outs for weaker samples and only little tear-out for strong samples. As references, bovine serum albumin and starch were used. Based on the combined data, we propose an overall model for the system and highlight how multiple variables affect performance. Adhesives, in particular, biobased ones, must be developed to be compatible with the overall adherend system for suitable infiltration and so that their mechanical properties match the adherend. The engineering of proteins gives an unmatched potential for designing adhesive systems that additionally have desired properties such as being fully water-based, biologically produced, and renewable.

KEYWORDS: cellulose, protein engineering, cellulose-binding domain, lap shear strength, bovine serum albumin, Araneus diadematus, adhesion, amino acid analysis

\section{INTRODUCTION}

There is currently a strong drive to develop new sustainable materials. For finding inspiration and new components, it is relevant to turn to the abundance of excellent materials found in nature. We should examine the use of natural components when developing a new material solution to enable sustainable and efficient use of raw materials. For wider use, we need not only to learn from natural materials but also to apply biological materials in new ways that are compatible with industrial processing. ${ }^{1,2}$

Here, we have focused on a new way of combining two wellknown and excellent materials, cellulose and silk, into an adhesive system taking advantage of the benefits of both materials. Cellulose is overall highly abundant and on the molecular level, it is an extremely strong and versatile polymer. ${ }^{3,4}$ To explore new processing methods for broader use of wood, including ways for recycling wood scrap or smaller pieces, there has recently been much interest in processes involving delignification. ${ }^{5}$ In delignification, the lignin fraction of wood is dissolved by immersion in an oxidizing bath in acidic conditions, leaving only cellulose and residual hemicellulose (Scheme 1A). The microstructure of the cell walls remains, and the loosened cellulose can be compressed and dried again. Excellent mechanical properties can be obtained since the optimal packing and close native alignment of cellulose fibrils are not disturbed. ${ }^{6}$ A further advantage is that the moldability of the wet cellulose allows it to be compressed into different shapes. For widening the range of use of delignified cellulose, one important development will be to find suitable adhesives that are compatible with its processing steps. New adhesives will allow combining individual pieces together into larger assemblies and could widen the range of use of delignified cellulose. ${ }^{5}$

For constructing samples, we applied a drying technique utilizing vacuum suction. ${ }^{7}$ The system has the benefit that it allows the use of wet, never-dried cellulose. Drying in vacuum also enables molding the material during the gluing process. ${ }^{8}$ Therefore, in adhesive systems for delignified cellulose, the processing in a wet state is particularly important. As a practical consideration, drying the cellulose in between delignification and bonding would be an unnecessary step. Also, the drying of cellulose would result in aggregation of fibers, which means that the open ultrastructure formed as a result of the

Received: October 15, 2021

Revised: December 13, 2021

Published: December 22, 2021

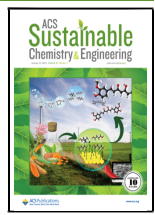


Scheme 1. Components and Preparation of the Adhesive System ${ }^{a}$

(A)
(B)

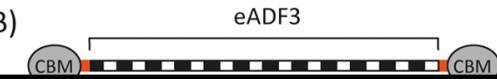

${ }^{a}$ (A) Delignification and densification steps, (B) overall structure of the CBM-eADF3-CBM protein used in this study as an adhesive, and (C) sample preparation for lap shear testing. Gluing of two sheets of veneer gave a set of seven sample strips for mechanical testing.

delignification would collapse, hampering the shaping and molding processes. ${ }^{9}$ Therefore, an important consideration for an adhesive for the delignified cellulose is whether it can function in an aqueous processing environment.

Silk proteins form a large and diverse family of proteins and are particularly interesting as biological adhesives. A large potential lies in the use of structurally engineered variants and production by recombinant expression systems. This would open a route toward sustainable and industrially scalable manufacturing. In addition to the well-known Bombyx mori silk and spider dragline silks, many organisms produce silk proteins for various adhesive or structural purposes. ${ }^{10}$ Overall, high toughness, cohesiveness, and adhesiveness are associated with many variants of silks. ${ }^{11-13}$ We worked here with a highly engineered variant of the spider Araneus diadematus ADF3protein, called eADF3, which was one of the first spider silks that was produced by recombinant means in Escherichia coli. ${ }^{14}$ The eADF3 sequence itself can be in a random coil form containing $\alpha$-helical structures when freshly prepared. As a step in its assembly process, it can undergo liquid-liquid phase separation (LLPS), forming a condensed phase of protein that can then further solidify, which leads to an increased $\beta$-sheet content. $^{15}$ More generally, LLPS has been suggested as an important intermediate step for several biological adhesives. ${ }^{16}$ Much of our understanding of LLPS comes from studies of adhesive mussel foot proteins. ${ }^{17}$

The structure of native spider silks includes folded modules in both termini of the disordered middle sequence. In the native protein structure, these terminal modules induce dimerization. ${ }^{18,19}$ Molecular structural engineering of silks, such as the module organization, allows introducing new functional properties. The variant CBM-eADF3-CBM that we used in the current work was engineered to have cellulosebinding modules (CBMs) as terminal modules (Scheme $1 \mathrm{~B}) .^{20}$ The CBMs show an affinity for cellulose and are naturally found, for example, to function as attachment modules in enzymes that degrade cellulose. ${ }^{21}$ In preliminary work, we identified that the combination of modules provides an adhesive function that none of the components by themselves have. ${ }^{15,22}$ Testing the fusion of CBMs without the middle silk module or the silk part alone was inferior to the full combination CBM-eADF3-CBM. Subsequent work involving computer modeling suggested that the overall triblock modular structure functions differently than the individual parts by promoting intramolecular interactions between protein molecules. ${ }^{23}$ It was suggested that the reason for this is that the terminal modules show dimerization interactions that work in synergy with the intermolecular interactions that the silk sequences show. ${ }^{24}$ In particular, the overall architecture affected the way in which condensates were formed and the internal structuring of the condensates into a bicontinuous network. ${ }^{23}$ The observed internal structuring indicates that the silk proteins are entangled and interact within the condensed phase. In general, internal network structuring has a significant role in polymer adhesion. ${ }^{25}$ However, the previously tested adhesive systems were based on paper-like materials and were overall not very strong due to the structurally relatively weak adherend. $^{22}$

In this work, as our experimental setup, we studied the lap shear strength of delignified wood veneers with the engineered CBM-eADF3-CBM as an adhesive. As a general reference adhesive, we chose bovine serum albumin (BSA) because it has widely been used as a protein adhesive in the past. It functions remarkably well and has even shown better performance than some types of recombinant silk proteins. ${ }^{26}$ Therefore, BSA is useful as a general benchmark reference that is also easily reproducible across the research community. As another reference adhesive, we used starch as it has been previously suggested as an adhesive for delignified wood. ${ }^{27}$

\section{EXPERIMENTAL SECTION}

Protein Expression in E. coli and Purification. The engineered silk protein CBM-eADF3-CBM having a triblock structure was made as previously described. ${ }^{20}$ Briefly, the modified ADF3 dragline sequence (eADF3) from $A$. diadematus was used as a middle block, to which folded CBM-terminal groups were fused by short linkers ( 2 





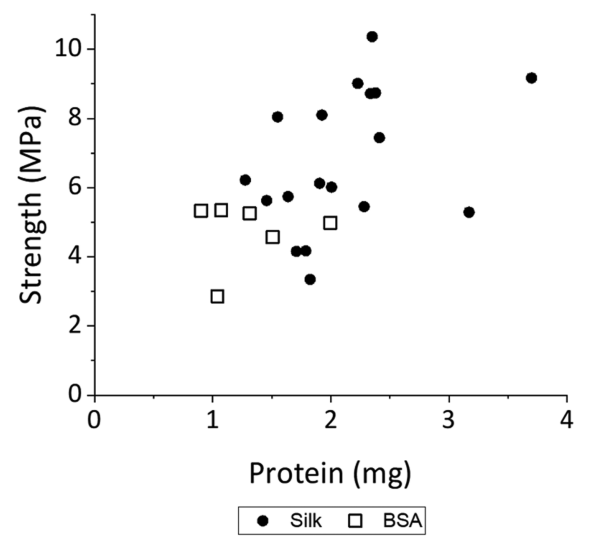

Figure 5. Lap shear strength as a function of protein that was retained in the $1 \mathrm{~cm}^{2}$ glue area. Good adhesion could be achieved even with low amounts of protein. The protein amount was determined using amino acid analysis.

the sample preparation. We detected only a little protein on the exterior surface, indicating that there was only little penetration of protein through thickness of the cellulose. This indicates that the protein does not easily impregnate the full thickness of the veneer and that capillary forces transport protein away from the site of application.

After the autoradiograph scan, the veneer was cut into $1 \mathrm{~cm}^{2}$ pieces. The cellulose was liquified by hydrolysis using a cellulase mixture after which the labeled protein was quantified by liquid scintillation counting. The spreading of the protein is shown as a heatmap in Figure 6B. We can conclude that only approximately $20 \%$ of the CBM-eADF3-CBM protein stayed within the bonding area. The remaining protein spread along the fiber direction so that about $40 \%$ was found within $1 \mathrm{~cm}$ of the applied region and the rest had spread outside that. We also noted that along the gluing area, there was variability in how the protein had spread.

To better understand the properties of CBM-eADF3-CBM as an adhesive, we measured its viscosity using oscillatory and rotational rheology measurements. We found that its viscosity was highly variable between samples, although sample preparation was done similarly. The zero-shear viscosity showed a broad range of 3-2300 Pa.s at concentrations between 94 and $124 \mathrm{gL}^{-1}$. The high values and the variability can both probably be ascribed to the coacervated state of the protein, as the coacervate droplets are viscous and also showed variability in their size between samples (Figure 7). As a comparison, a $80 \mathrm{gL}^{-1}$ BSA solution had a significantly lower zero-shear viscosity range of $2-5 \mathrm{~Pa} \cdot \mathrm{s}$. The starch paste at 16.5 wt \% showed much high zero-shear viscosity values in the range of 5000-12 $000 \mathrm{~Pa} \cdot \mathrm{s}$ (see the Supporting Information).

The use of lap shear testing to compare adhesives requires caution as they are affected by parameters such as bending and strain distribution that may vary significantly between systems. ${ }^{31}$ Ductility of both adherend and adhesive affects results greatly. ${ }^{32}$ For this reason, standardized testing procedures are generally useful to enable comparison between adhesives. However, for the delignified cellulose system under study here, no standard systems are available as it is a new experimental system. Earlier, BSA and recombinant spider silk were compared in a system in which glass was used as an adherend. In that study, BSA outperformed recombinant spider silk as an adhesive (8.3 $\mathrm{MPa}$ for BSA, 6.2 $\mathrm{MPa}$ for silk). ${ }^{26}$ However, both adhesives were very weak on less stiff adherends. A direct comparison to the present system is, therefore, difficult as glass is stiff with Young's modulus around $50 \mathrm{GPa}$, while the delignified and compressed cellulose here

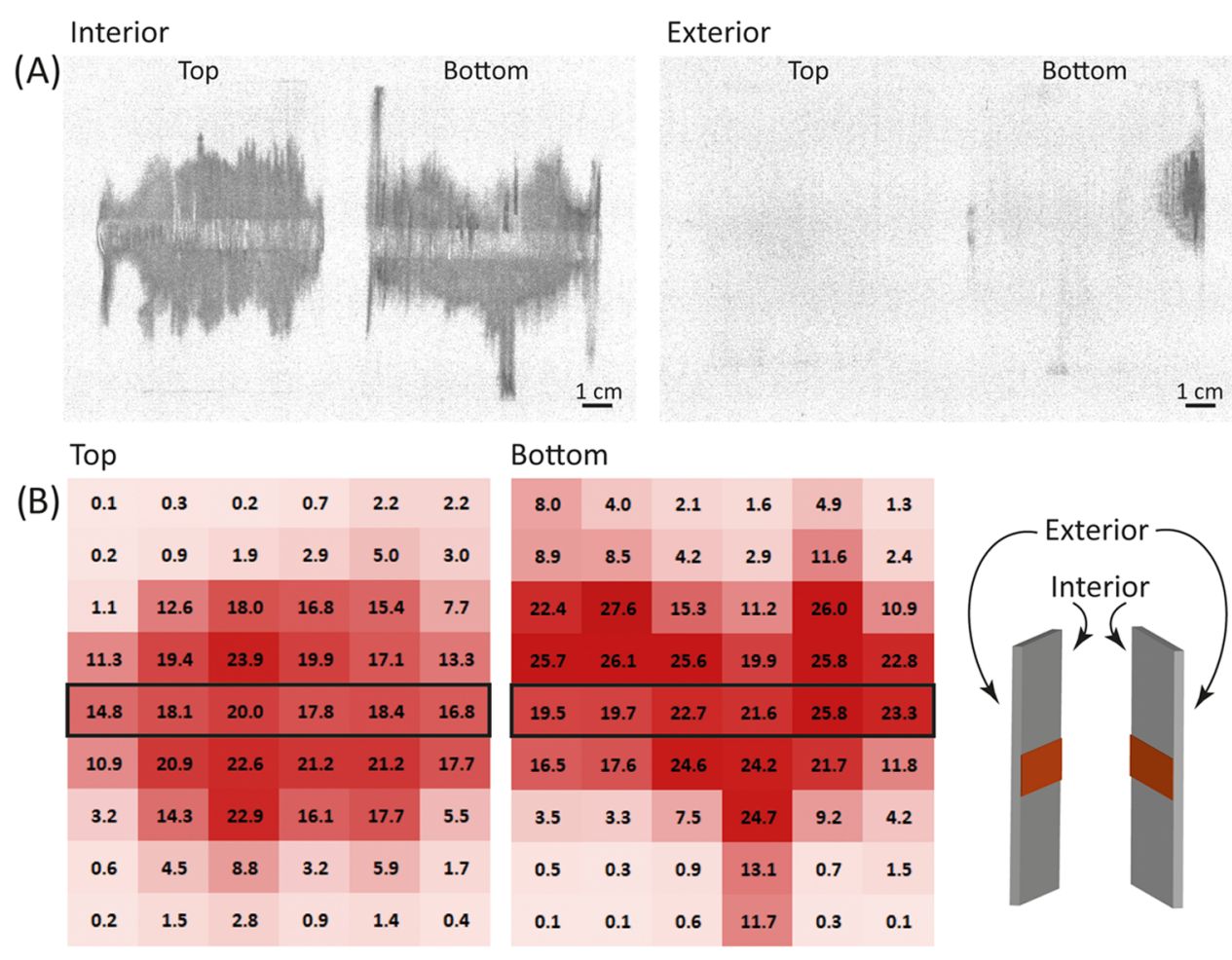

Figure 6. (A) ${ }^{3} \mathrm{H}$-autoradiographs of the veneer sheets showing the spread of protein. (B) Heatmap showing the spread of protein within the veneer sheets. Values represent the radioactivity in $\mathrm{kBq}$ measured from each $\mathrm{cm}^{2}$. The glue area is indicated with a square. 

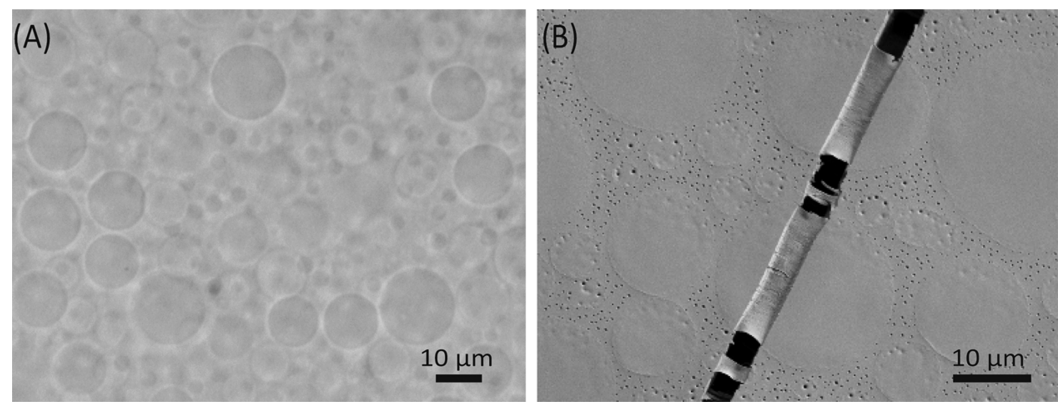

Figure 7. (A) Optical micrograph of the appearance of a typical sample of CBM-eADF3-CBM before application onto the gluing area, showing the coacervated state of the protein. (B) SEM images of CBM-eADF3-CBM coacervates that had been stretched after allowing most of the water to evaporate, resulting in a crack. Bridging over the cracks through coacervates shows a tear-out of protein and suggests interactions or entanglements of the proteins.

\section{Scheme 2. Mechanisms in Lap Shear Testing ${ }^{a}$}
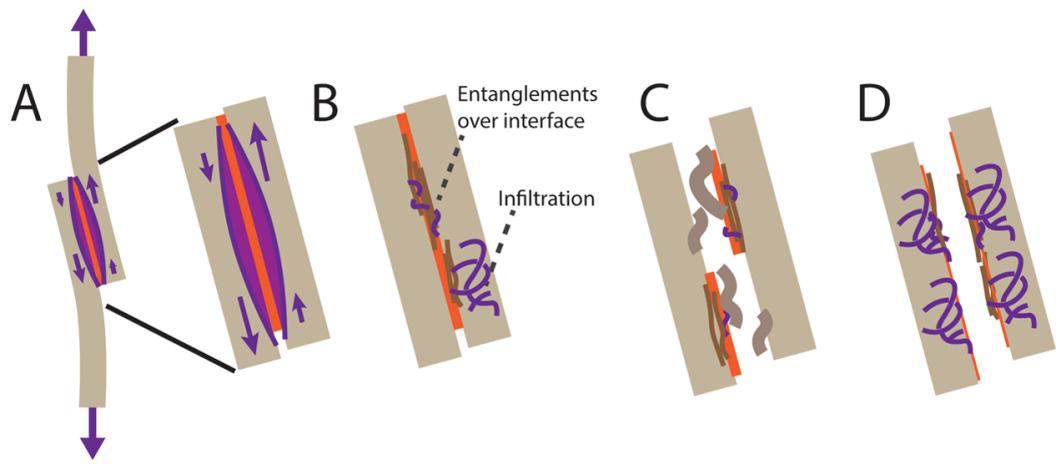

${ }^{a}$ (A) In the lap shear test, the uneven strain in the adherend creates stresses within the interfacial region and within the adherend. (B) In particular, two mechanisms are important for the strength of the lap joint: entanglements over the interface and adhesive infiltration. (C) Poor infiltration can lead to large strains in the near interfacial region and a weak bond. A large tear-out would result. (D) A good infiltration can strengthen the near interfacial region leading to adhesive failure in the interface and little tear-out.

was around $10 \mathrm{GPa}$. A number of other details, such as processing, also suggest that different mechanisms were at play. For a very stiff adherend such as glass, a highly cross-linked and brittle adhesive can give excellent strength. In one extreme example, very stiff cellulose nanocrystals were carefully assembled as an adhesive layer between two glass slides giving a high lap strength of $7 \mathrm{MPa}$. Consequently, due to the high stiffness of the system, the bonding was extremely brittle, breaking at less than $0.08 \mathrm{MPa}$ if the force was applied from the side. ${ }^{33}$ Therefore, such a system would be expected to be very weak on a more easily yielding adherend.

In another study with similar goals, cross-linking chemistry was used to improve BSA as an adhesive for wood. ${ }^{34}$ Without cross-linking, BSA gave a strength of $0.1 \mathrm{MPa}$, and when optimized with cross-linkers, the adhesion increased to $4 \mathrm{MPa}$. However, direct comparisons with the current study are difficult since so many factors, in particular, the adherend, differ. We also note that in our current study, testing wood as the adherend gave very low strength. The reason for these results remained unexplored but could be that wood requires better cohesion in the adhesive over larger distances due to irregularities in its structure. Nonetheless, we note that there are several reports in which a variety of adherends and optimizations of treatments show a good potential of proteins. ${ }^{35}$ Of protein-based adhesives, soy protein has been studied extensively (2-8 MPa)..$^{34,36,37}$ The highest values are typically obtained in cross-linked systems, with examples including modified BSA $(4 \mathrm{MPa}),{ }^{34}$ gluten $(2 \mathrm{MPa}),{ }^{38}$ corn zein $(8 \mathrm{MPa}),{ }^{39}$ and starch $(7.8 \mathrm{MPa}) .^{40}$

In the current work, as the adherend is not very stiff, it is expected that the adhesive should show deformability to accommodate for strain in the sample. ${ }^{32}$ Such strain occurs in the lap joint because of the distortion of the sample at the joint due to, e.g., adherend stretching. ${ }^{31}$ Effects of infiltration of the near interfacial region have been discussed in the literature and are generally seen as leading to an off-loading of the lap joint because forces are more evenly distributed due to the adhesive penetration. ${ }^{41}$ Starch is a stiffer molecule than BSA and has more extended polymer chains and much higher viscosity. The high observed tear-out for starch indicates that although it did bind strongly, and it did not infiltrate the adherend. This is expected since the molecular mass of starch is high. It is likely that it formed a surface layer that pulled out cellulose fibrils from the adhered upon failure. BSA with its smaller molecular size and low viscosity could infiltrate the adherend, resulting in cohesiveness within the near interfacial region of the adherend. Because cellulose fibrils are more closely packed, better cohesion would form within the near interfacial region compared to the joint interface. This is because the interface between adherends does not have equally good packing and alignment of cellulose fibrils as within the adherend, leading to larger gaps and longer bonding distances. Hence, BSA would show low tear-out upon failure.

The large differences in tear-out between high and lowstrength silk samples suggest a shift in the mechanism of 
adhesive failure between the samples. In general, it has been suggested that for polymeric adhesives, chain entanglements are critical for forming good contacts over the interface and creating good cohesiveness. ${ }^{25,42-44}$ In Scheme 2, we summarize our interpretation of the underlying mechanisms. It seems likely that in the high-strength samples, silk had been able to both infiltrate the adherend sufficiently and at the same time provide a good cohesion over the interface. In the lowstrength samples, it seems that infiltration below the interface was insufficient in comparison. This hypothesis is supported by the noted high tear-out and the finding that silk could sometimes show a high viscosity. We, therefore, find it possible that the large tear-out in the weakest CBM-eADF3-CBM silk samples resulted from a failure to create bonding below the interface, i.e., in the near interfacial region. Upon the failure of these weaker samples, a fairly large tear-out results as the bridging of the interface would be relatively strong, but the low infiltration led to the failure of fiber interactions deeper inside the cellulose adherend (Scheme 2C). Even with low infiltration, they could give a cohesive bridging over the interface, possibly supported by the molecular entanglement to which coacervation and relatively long chain lengths lead (Figure 7). The strongest silk samples would then have achieved a good infiltration beneath the interfacial region as well as provided good bridging over the interface, resulting in a smooth fracture surface and an overall strong bond (Scheme 2D).

The reasons for the relatively large variability in adhesive strength of the CBM-eADF3-CBM silk adhesive samples remained unclear but can be related to the very broad range of viscosity that different silk samples showed. Previously, it has been shown that the viscosity is dependent on the phase separation of the silk protein due to intermolecular interactions between the silk molecules. ${ }^{22}$ Furthermore, viscosity of coacervates has also in other contexts been proposed as means of regulating the extent of protein infiltration into porous scaffolds. ${ }^{45}$ Unfortunately, in our setup, it was not possible to measure the viscosity of silk used in each experiment since even application on the rheometer and removal could result in irreproducible processing of the protein. Also, gelling and precipitation occurred, rendering samples unusable. Therefore, a technical problem is the unpredictability of exactly how and at which stage the viscosity of the coacervated CBM-eADF3-CBM sample changed.

\section{CONCLUSIONS}

In conclusion, we have shown how recombinant silk protein in combination with delignified wood forms a strong adhesive system. The work shows a direction for future materials in which we utilize natural components to a maximal extent, but in a way that processing could be scaled and performed industrially. In particular, the adhesive processing system was fully aqueous. We have only recently gained an understanding of how the assembly of recombinant proteins on a molecular level can be controlled ${ }^{20}$ and we highlight the potential of using them for new materials. The work also relies on the underlying work on understanding how biological materials, in particular, composite structures, function. ${ }^{1,43}$ The potential advantage is simplicity; we used no cross-linkers or other modifiers. The work highlights that high performance can be obtained in fully biobased approaches with aqueous processability as will be required for future sustainable materials with a low environmental burden. We see an opportunity in continued structural modification of the recombinant protein to further enhance its properties.

\section{ASSOCIATED CONTENT}

\section{(3) Supporting Information}

The Supporting Information is available free of charge at https://pubs.acs.org/doi/10.1021/acssuschemeng.1c07043.

Data from rheological characterizations of CBM-eADF3$\mathrm{CBM}$, starch, and BSA adhesives (PDF)

\section{AUTHOR INFORMATION}

\section{Corresponding Author}

Markus B. Linder - Department of Bioproducts and Biosystems, Aalto University, 02150 Espoo, Finland; (1) orcid.org/0000-0002-7271-6441;

Email: markus.linder@aalto.fi

\section{Authors}

Laura Lemetti - Department of Bioproducts and Biosystems, Aalto University, 02150 Espoo, Finland; orcid.org/00000003-1845-752X

Jennifer Tersteegen - Department of Bioproducts and Biosystems, Aalto University, 02150 Espoo, Finland; (1) orcid.org/0000-0002-7356-0186

Juuso Sammaljärvi - Department of Chemistry, University of Helsinki, 00014 Helsinki, Finland

A. Sesilja Aranko - Department of Bioproducts and Biosystems, Aalto University, 02150 Espoo, Finland; (1) orcid.org/0000-0001-9425-3524

Complete contact information is available at:

https://pubs.acs.org/10.1021/acssuschemeng.1c07043

\section{Funding}

This work was performed within the project "Strong Composite" supported under the umbrella of ERANET Cofund ForestValue, funded by Academy of Finland projects \#308772, \#317395, \#326345, and \#333238. The authors are grateful for the support by the FinnCERES Materials Bioeconomy Ecosystem, the Bioeconomy Infrastructure, and the OtaNano-Nanomicroscopy Center (Aalto-NMC) at Aalto University.

Notes

The authors declare no competing financial interest.

\section{ACKNOWLEDGMENTS}

The authors thank professor Ingo Burgert and his team at ETH Zürich for helping us to establish delignification and compression setups. They also thank Dr. Isabell Tunn for help with rheology measurements and Teemu Välisalmi for help with Welch's test.

\section{REFERENCES}

(1) Wegst, U. G. K.; Bai, H.; Saiz, E.; Tomsia, A. P.; Ritchie, R. O. Bioinspired Structural Materials. Nat. Mater. 2015, 14, 23-36.

(2) Byrne, G.; Dimitrov, D.; Monostori, L.; Teti, R.; van Houten, F.; Wertheim, R. Biologicalisation: Biological Transformation in Manufacturing. CIRP J. Manuf. Sci. Technol. 2018, 21, 1-32.

(3) Li, T.; Chen, C.; Brozena, A. H.; Zhu, J. Y.; Xu, L.; Driemeier, C.; Dai, J.; Rojas, O. J.; Isogai, A.; Wågberg, L.; Hu, L. Developing Fibrillated Cellulose as a Sustainable Technological Material. Nature 2021, 590, 47-56.

(4) Heise, K.; Kontturi, E.; Allahverdiyeva, Y.; Tammelin, T.; Linder, M. B.; Nonappa; Ikkala, O. Nanocellulose: Recent Fundamental 
Advances and Emerging Biological and Biomimicking Applications. Adv. Mater. 2021, 33, No. 2004349.

(5) Frey, M.; Widner, D.; Segmehl, J. S.; Casdorff, K.; Keplinger, T.; Burgert, I. Delignified and Densified Cellulose Bulk Materials with Excellent Tensile Properties for Sustainable Engineering. Appl. Mater. Interfaces 2018, 10, 5030-5037.

(6) Frey, M.; Schneider, L.; Masania, K.; Keplinger, T.; Burgert, I. Delignified Wood-Polymer Interpenetrating Composites Exceeding the Rule of Mixtures. ACS Appl. Mater. Interfaces 2019, 11, 3530535311.

(7) Frey, M.; Zirkelbach, M.; Dransfeld, C.; Faude, E.; Trachsel, E.; Hannus, M.; Burgert, I.; Keplinger, T. Fabrication and Design of Wood-Based High-Performance Composites. J. Vis. Exp. 2019, 153, No. e60327.

(8) Frey, M.; Biffi, G.; Adobes-Vidal, M.; Zirkelbach, M.; Wang, Y.; Tu, K.; Hirt, A. M.; Masania, K.; Burgert, I.; Keplinger, T. Tunable Wood by Reversible Interlocking and Bioinspired Mechanical Gradients. Adv. Sci. 2019, 6, No. 1802190.

(9) Pönni, R.; Kontturi, E.; Vuorinen, T. Accessibility of Cellulose: Structural Changes and Their Reversibility in Aqueous Media. Carbohydr. Polym. 2013, 93, 424-429.

(10) Sutherland, T. D.; Young, J. H.; Weisman, S.; Hayashi, C. Y.; Merritt, D. J. Insect Silk: One Name, Many Materials. Annu. Rev. Entomol. 2010, 55, 171-188.

(11) Smith, B. L.; Schäffer, T. E.; Viani, M.; Thompson, J. B.; Frederick, N. A.; Kindt, J.; Belcher, A.; Stucky, G. D.; Morse, D. E.; Hansma, P. K. Molecular Mechanistic Origin of the Toughness of Natural Adhesives, Fibres and Composites. Nature 1999, 399, 761763.

(12) Pasche, D.; Horbelt, N.; Marin, F.; Motreuil, S.; Fratzl, P.; Harrington, M. J. Self-Healing Silk from the Sea: Role of Helical Hierarchical Structure in Pinna Nobilis Byssus Mechanics. Soft Matter 2019, 15, 9654-9664.

(13) Sahni, V.; Blackledge, T. A.; Dhinojwala, A. A Review on Spider Silk Adhesion. J. Adhes. 2011, 87, 595-614.

(14) Huemmerich, D.; Helsen, C. W.; Quedzuweit, S.; Oschmann, J.; Rudolph, R.; Scheibel, T. Primary Structure Elements of Spider Dragline Silks and Their Contribution to Protein Solubility. Biochemistry 2004, 43, 13604-13612.

(15) Mohammadi, P.; Aranko, A. S.; Landowski, C. P.; Ikkala, O.; Jaudzems, K.; Wagermaier, W.; Linder, M. B. Biomimetic Composites with Enhanced Toughening Using Silk-Inspired Triblock Proteins and Aligned Nanocellulose Reinforcements. Sci. Adv. 2019, 5, No. eaaw2541.

(16) Sun, Y.; Lim, Z. W.; Guo, Q.; Yu, J.; Miserez, A. Liquid-Liquid Phase Separation of Proteins and Peptides Derived from Biological Materials: Discovery, Protein Engineering, and Emerging Applications. MRS Bull. 2020, 45, 1039-1047.

(17) Waite, J. H. Mussel Adhesion - Essential Footwork. J. Exp. Biol. 2017, 220, 517-530.

(18) Hagn, F.; Eisoldt, L.; Hardy, J. G.; Vendrely, C.; Coles, M.; Scheibel, T.; Kessler, H. A Conserved Spider Silk Domain Acts as a Molecular Switch That Controls Fibre Assembly. Nature 2010, 465, 239-242.

(19) Askarieh, G.; Hedhammar, M.; Nordling, K.; Saenz, A.; Casals, C.; Rising, A.; Johansson, J.; Knight, S. D. Self-Assembly of Spider Silk Proteins Is Controlled by a PH-Sensitive Relay. Nature 2010, 465, 236-238.

(20) Mohammadi, P.; Aranko, A. S.; Lemetti, L.; Cenev, Z.; Zhou, Q.; Virtanen, S.; Landowski, C. P.; Penttilä, M.; Fischer, W. J.; Wagermaier, W.; Linder, M. B. Phase Transitions as Intermediate Steps in the Formation of Molecularly Engineered Protein Fibers. Commun. Biol. 2018, 1, No. 86.

(21) Griffo, A.; Rooijakkers, B. J. M.; Hähl, H.; Jacobs, K.; Linder, M. B.; Laaksonen, P. Binding Forces of Cellulose Binding Modules on Cellulosic Nanomaterials. Biomacromolecules 2019, 20, 769-777.

(22) Mohammadi, P.; Beaune, G.; Stokke, B. T.; Timonen, J. V. I.; Linder, M. B. Self-Coacervation of a Silk-Like Protein and Its Use As an Adhesive for Cellulosic Materials. ACS Macro Lett. 2018, 7, 11201125.

(23) Batys, P.; Fedorov, D.; Mohammadi, P.; Lemetti, L.; Linder, M. B.; Sammalkorpi, M. Self-Assembly of Silk-like Protein into Nanoscale Bicontinuous Networks under Phase-Separation Conditions. Biomacromolecules 2021, 22, 690-700.

(24) Fedorov, D.; Batys, P.; Hayes, D. B.; Sammalkorpi, M.; Linder, M. B. Analyzing the Weak Dimerization of a Cellulose Binding Module by Analytical Ultracentrifugation. Int. J. Biol. Macromol. 2020, 163, 1995-2004.

(25) Raos, G.; Zappone, B. Polymer Adhesion: Seeking New Solutions for an Old Problem. Macromolecules 2021, DOI: 10.1021/ acs.macromol.1c01182.

(26) Roberts, A. D.; Finnigan, W.; Kelly, P. P.; Faulkner, M.; Breitling, R.; Takano, E.; Scrutton, N. S.; Blaker, J. J.; Hay, S. NonCovalent Protein-Based Adhesives for Transparent SubstratesBovine Serum Albumin vs. Recombinant Spider Silk. Mater. Today Bio. 2020, 7, No. 100068.

(27) Frey, M.; Schneider, L.; Razi, H.; Trachsel, E.; Faude, E.; Koch, S. M.; Masania, K.; Fratzl, P.; Keplinger, T.; Burgert, I. HighPerformance All-Bio-Based Laminates Derived from Delignified Wood. ACS Sustainable Chem. Eng. 2021, 9, 9638-9646.

(28) Li, K.; Clarkson, C. M.; Wang, L.; Liu, Y.; Lamm, M.; Pang, Z.; Zhou, Y.; Qian, J.; Tajvidi, M.; Gardner, D. J.; Tekinalp, H.; Hu, L.; Li, T.; Ragauskas, A. J.; Youngblood, J. P.; Ozcan, S. Alignment of Cellulose Nanofibers: Harnessing Nanoscale Properties to Macroscale Benefits. ACS Nano 2021, 15, 3646-3673.

(29) Ansari, F.; Berglund, L. A. Toward Semistructural Cellulose Nanocomposites: The Need for Scalable Processing and Interface Tailoring. Biomacromolecules 2018, 19, 2341-2350.

(30) Nishiyama, Y. Molecular Interactions in Nanocellulose Assembly. Philos. Trans. R. Soc. Math. Phys. Eng. Sci. 2018, 376, No. 20170047.

(31) Abbott, S. Adhesion Science: Principles and Practice; Destech Publications: Lancaster, USA.

(32) Mazzotta, M. G.; Putnam, A. A.; North, M. A.; Wilker, J. J. Weak Bonds in a Biomimetic Adhesive Enhance Toughness and Performance. J. Am. Chem. Soc. 2020, 142, 4762-4768.

(33) Tardy, B. L.; Richardson, J. J.; Greca, L. G.; Guo, J.; Ejima, H.; Rojas, O. J. Exploiting Supramolecular Interactions from Polymeric Colloids for Strong Anisotropic Adhesion between Solid Surfaces. Adv. Mater. 2020, 32, No. 1906886.

(34) Román, J. K.; Wilker, J. J. Cooking Chemistry Transforms Proteins into High-Strength Adhesives. J. Am. Chem. Soc. 2019, 141, 1359-1365.

(35) Imam, S. H.; Bilbao-Sainz, C.; Chiou, B.-S.; Glenn, G. M.; Orts, W. J. Biobased Adhesives, Gums, Emulsions, and Binders: Current Trends and Future Prospects. J. Adhes. Sci. Technol. 2013, 27, 19721997.

(36) Zeng, Y.; Xu, P.; Yang, W.; Chu, H.; Wang, W.; Dong, W.; Chen, M.; Bai, H.; Ma, P. Soy Protein-Based Adhesive with Superior Bonding Strength and Water Resistance by Designing Densely Crosslinking Networks. Eur. Polym. J. 2021, 142, No. 110128.

(37) Wang, Z.; Zhao, S.; Pang, H.; Zhang, W.; Zhang, S.; Li, J. Developing Eco-Friendly High-Strength Soy Adhesives with Improved Ductility through Multiphase Core-Shell Hyperbranched Polysiloxane. ACS Sustainable Chem. Eng. 2019, 7, 7784-7794.

(38) Xi, X.; Pizzi, A.; Gerardin, C.; Liao, J.; Amirou, S.; Abdalla, S. Glutaraldehyde-Wheat Gluten Protein Adhesives for Wood Bonding. J. Adhes. 2021, 97, 88-100.

(39) Schmidt, G.; Woods, J. T.; Fung, L. X. B.; Gilpin, C. J.; Hamaker, B. R.; Wilker, J. J. Strong Adhesives from Corn Protein and Tannic Acid. Adv. Sustainable Syst. 2019, 3, No. 1900077.

(40) Zhang, Y.; Ding, L.; Gu, J.; Tan, H.; Zhu, L. Preparation and Properties of a Starch-Based Wood Adhesive with High Bonding Strength and Water Resistance. Carbohydr. Polym. 2015, 115, 32-37.

(41) Averina, E.; Konnerth, J.; D'Amico, S.; van Herwijnen, H. W. G. Protein Adhesives: Alkaline Hydrolysis of Different Crop Proteins 
as Modification for Improved Wood Bonding Performance. Ind. Crops Prod. 2021, 161, No. 113187.

(42) Fratzl, P.; Burgert, I.; Gupta, H. S. On the Role of Interface Polymers for the Mechanics of Natural Polymeric Composites. Phys. Chem. Chem. Phys. 2004, 6, 5575-5579.

(43) Studart, A. R. Towards High-Performance Bioinspired Composites. Adv. Mater. 2012, 24, 5024-5044.

(44) Wool, R. P. Polymer Entanglements. Macromolecules 1993, 26, $1564-1569$.

(45) Tan, Y.; Hoon, S.; Guerette, P. A.; Wei, W.; Ghadban, A.; Hao, C.; Miserez, A.; Waite, J. H. Infiltration of Chitin by Protein Coacervates Defines the Squid Beak Mechanical Gradient. Nat. Chem. Biol. 2015, 11, 488-495.

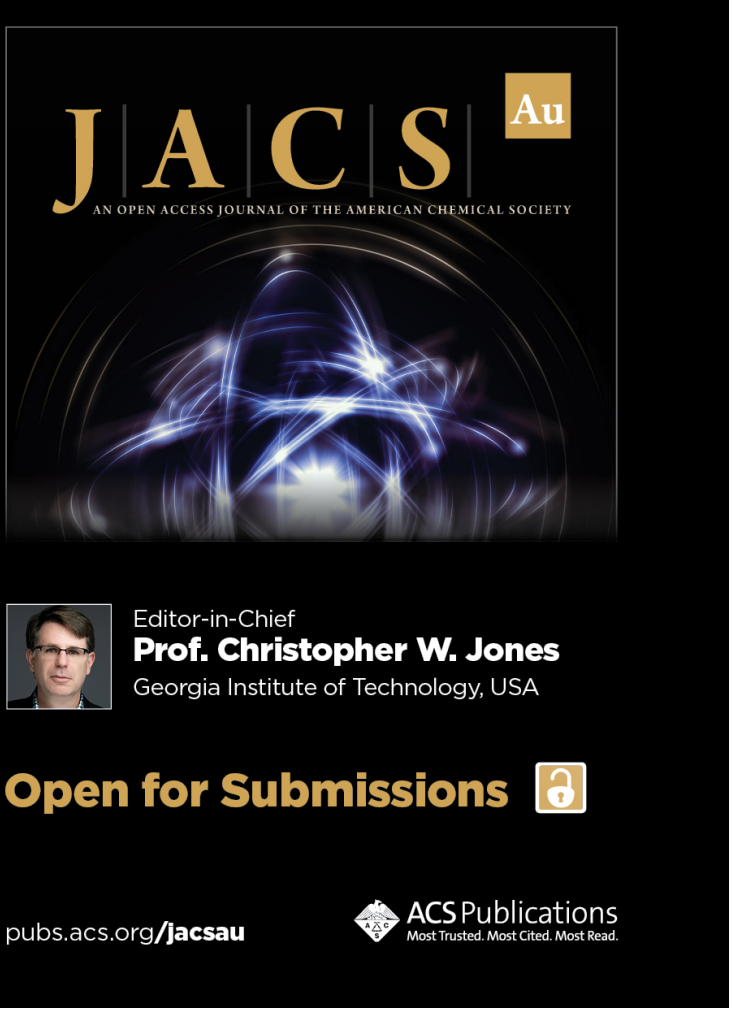

